\title{
Small Size Patch Antenna with DGS for Emergency Management
}

\author{
Sushil Kakkar ${ }^{1, a}$, T. S. Kamal ${ }^{2}$ and A. P. Singh ${ }^{3}$ \\ ${ }^{1}$ Research Scholar, IKG PTU, Jalandhar \\ ${ }^{2} E C E$ Department, RIET, Abhohar, Punjab, India \\ ${ }^{3}$ ECE Department, SLIET, Logowal
}

\begin{abstract}
In this paper a small size patch antenna with defected ground structure (DGS) is designed for emergency management applications. The microstrip fed antenna is consisting of rectangular shape partial ground plane and meander line shaped DGS is optimized. The resonant performance of the proposed antenna has been illustrated using method of moment based IE3D EM simulator. The antenna is designed to resonate at $4.94 \mathrm{GHz}$ frequency and possesses the properties of good performance, compact size, low profile and low cost, therefore it is feasible for practical applications in Emergency Management.
\end{abstract}

\section{Introduction}

The booming progress in wireless communication system and an increasing demand to integrate different technologies in to small user equipment has remarkably increase the fashion of introducing compact antennas [1]. Microstrip patch antenna, because of its small size, low profile, low manufacturing cost and ease of integration with feed networks, is find extensive applications in wireless communication system [2-3]. In order to further improve the dimensional and resonant characteristics of the patch antennas, several initiatives have been taken in last decade such as slot in the patch, slot in the feed line, fractal geometries, using partial ground planes, DGS and many more [4-6]. Among them DGS is gaining popularity in a very faster way. DGS can be obtained by etching off a simple shape from ground plane [7, 8].

In this paper a meander line shaped DGS has been utilized in the partial ground plane of small size patch antenna. The implementation of DGS is responsible for the fine tuning and wider bandwidth of the presented antenna, to make it feasible for emergency management applications. A fundamental element of an emergency system is a reliable communication infrastructure allowing rescue operators to be connected and able to support the collection and the elaboration of data coming from monitoring devices distributed in the area of the disaster.

\section{Designs and Structure}

The proposed antenna structure is a simple patch antenna with square shape having side of the square $(\mathrm{S})$ of 15 $\mathrm{mm}$. The feeding strip is designed in such a way to obtain 50 ohms impedance. The width of the strip (W) is $5 \mathrm{~mm}$.
Rectangular shape is the candidate structure for the partial ground plane. In order to further enhance the resonating performance of the proposed antenna, a small size meander shape DGS has been introduced in the ground plane. The length (L) of the DGS is $10 \mathrm{~mm}$ and width (W1) of the defect is $1 \mathrm{~mm}$. The structure of the proposed antenna with and without DGS has been shown in figure 1.

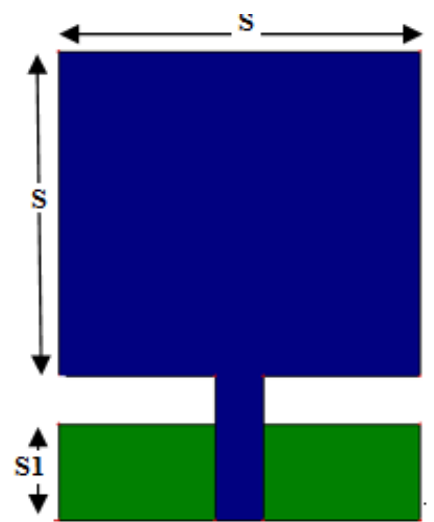

(a)

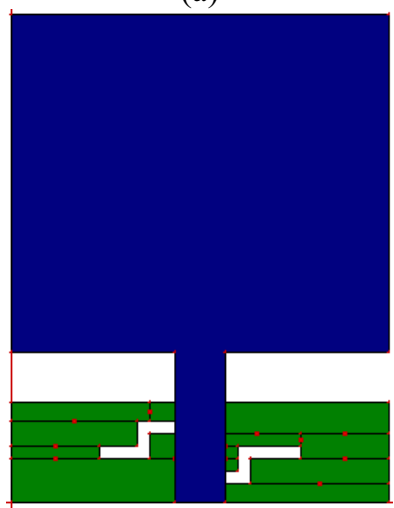

(b)

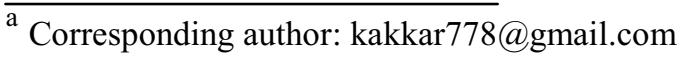




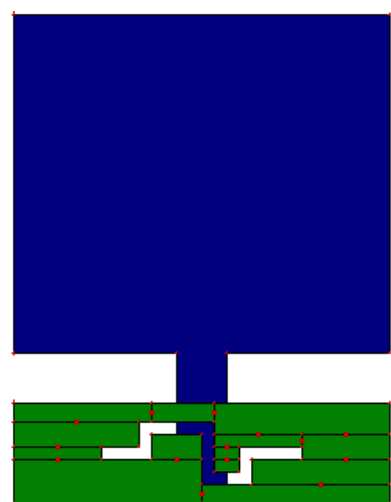

(c)

Figure 1. Geometry of proposed antenna (a) without DGS (b) with DGS top view (c) with DGS bottom view

\section{Results and Discussion}

The simulation tool adopted for evaluating the performance of the proposed antennas is IE3D software, which exploits the method of moments to solve the electric field integral equation.

\subsection{Resonating Characteristics}

Figure 2 shows the s-parameters of reference antenna and proposed antenna with meander shaped DGS and from the figure it is clear that the proposed antenna resonate at $4.94 \mathrm{GHz}$ with return loss $-20.56 \mathrm{dBi}$ and reference antenna resonates at $5.39 \mathrm{GHz}$ with return loss -12.46 $\mathrm{dBi}$. The implementation of meander shaped DGS in ground plane make the proposed antenna feasible for emergency management applications. The detailed comparison between with and without DGS structure is given in Table 1.

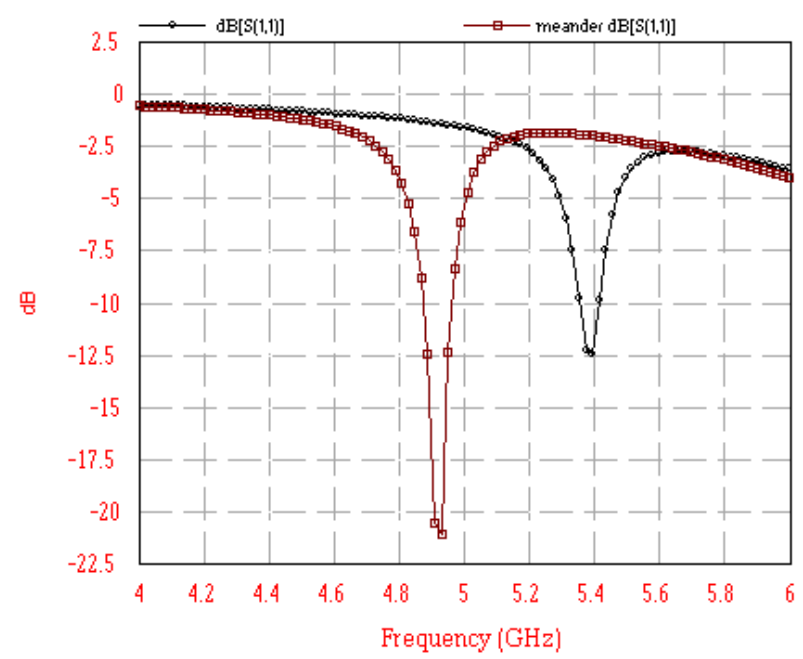

Figure 2. S11 parameter comparisons between proposed antenna and reference antenna.
Table 1. Comparison of proposed and reference antenna.

\begin{tabular}{|c|c|c|c|c|}
\hline Design & $\begin{array}{c}\text { Resonating } \\
\text { Frequency } \\
(\mathrm{GHz})\end{array}$ & $\begin{array}{c}\text { Return } \\
\text { Loss }\end{array}$ & VSWR & $\begin{array}{c}\text { Bandwidt } \\
\mathrm{h}(\mathrm{GHz})\end{array}$ \\
\hline $\begin{array}{c}\text { Reference } \\
\text { Antenna }\end{array}$ & 5.39 & -12.46 & 1.62 & 0.04 \\
\hline $\begin{array}{c}\text { Proposed } \\
\text { Antenna }\end{array}$ & 4.94 & -20.56 & 1.20 & 0.11 \\
\hline
\end{tabular}

\subsection{Input Impedance}

The input impedance properties of reference and proposed antenna are shown in figure 3. It may be noticed that the input impedance of reference antenna is $60.3 \mathrm{ohms}$ whereas for proposed antenna it is $53.27 \mathrm{ohms}$ which means that proposed structure possesses better impedance matching than reference structure.

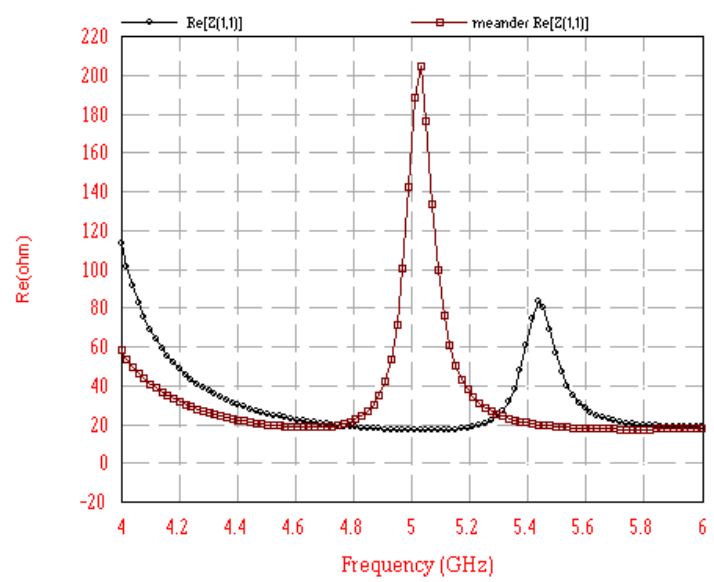

Figure 3. Input Impedance comparisons between proposed antenna and reference antenna.

\subsection{Radiation Characteristics}

The radiation characteristic of proposed patch antenna is shown in Figure 4. The radiation pattern is symmetrical to antenna axis in E-plane and pattern in H-plane is nearly omnidirectional

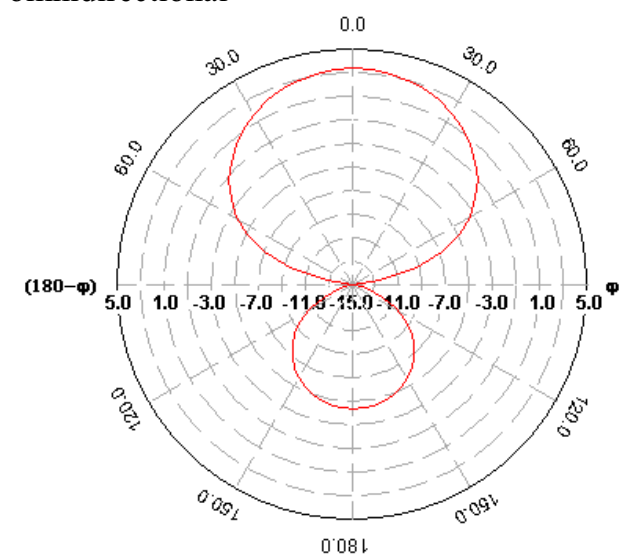

(a) 


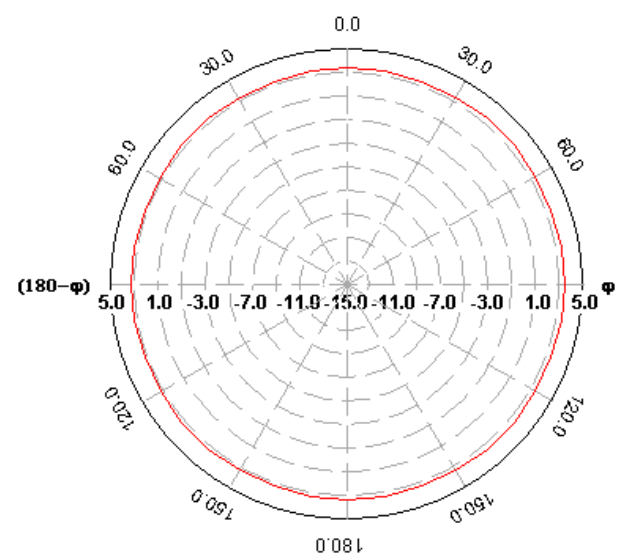

(b)

Figure 4. Radiation characteristics of proposed antenna (a) Eplane (b) H-plane

\subsection{Gain}

The gain vs. frequency plot of proposed antenna with DGS is shown in figure. 5. The maximum achievable gain of the antenna is $4.26 \mathrm{dBi}$ at $4.94 \mathrm{GHz}$ resonant frequency.

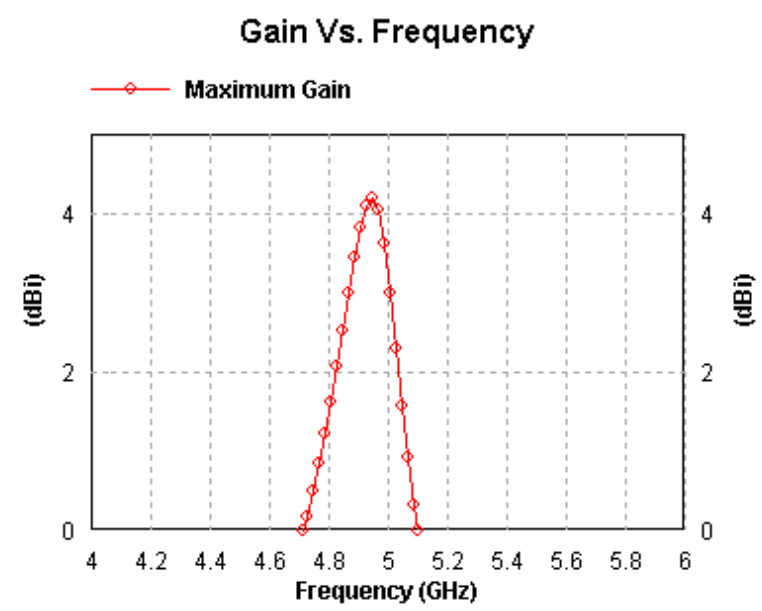

Figure 5 Gain of proposed antenna

\section{Conclusion}

The design and analysis of small size patch antenna with and without meander shape DGS is presented in this paper. In order to obtain the effect of DGS, critical simulated study has been done using IE3D simulator. The presented results reveal that the proposed antenna with DGS provides better impedance matching and wider bandwidth than its original structure. The proposed antenna is small size, low profile antenna that can be used for emergency management applications.

\section{References}

1. Weng et. al, "An Overview on Defected Ground Structure", Progress In Electromagnetics Research B", Vol. 7, 173-189, (2008)

2. D. Schlieter and R. Henderson, "High Q Defected Ground Structures in Grounded Coplanar
Waveguide", Electronic Letters, Vol. 48, no. 11, (2012)

3. S. Rani and A. P. Singh, "Fractal Antenna with Defected Ground Structure for Telemedicine Applications," International journal on Communications, Antenna and Propagation, vol.1, pp. 1-15, (2012)

4. A. Arya, M. Kartikeyan and A. Patnaik, "On the Size Reduction of Microstrip Antenna Using DGS", Proceedings of IEEE Conference, (2010)

5. A. Nouri and G. Dadashzadeh, "A Compact UWB Band-Notched Printed Monopole Antenna with Defected Ground Structure", IEEE Antennas and Wireless Propagation Letters, Vol. 10, (2011)

6. S. Rani and A. P. Singh, "On the Design and Optimization of New Fractal Antenna Using PSO", International Journal of Electronics, vol. 100, no. 10, pp. 1383-1397, (2012)

7. S. Kakkar, S. Rani and A. P. Singh, On the Resonant Behaviour Analysis of Small-Size Slot Antenna with Different Substrates, International Journal of Computer Applications, pp. no. 10-12, (2012)

8. R. Azaro, L. Debiasi, M. Benedetti, P. Rocca and A. Massa, "A Hybrid Prefractal Three-Band Antenna for Multistandard mobile Wireless Applications", IEEE Antennas and Wireless Propagation Letters, vol.8, pp. 905-908, (2009) 